\title{
Dementia and aphasia in motor neuron disease: an underrecognised association?
}

\author{
Wojtek P Rakowicz, John R Hodges
}

\begin{abstract}
Objectives-To determine the prevalence and nature of global cognitive dysfunction and language deficits in an unselected population based cohort of patients with motor neuron disease (MND).

Methods_-A battery of neuropsychological and language tests was administered to patients presenting consecutively over a 3 year period to a regional neurology service with a new diagnosis of sporadic motor neuron disease.

Results-The 18 patients could be divided on the basis of their performance into three groups: Three patients were demented and had impaired language function (group 1); two non-demented patients had an aphasic syndrome characterised by word finding difficulties and anomia (group 2). Major cognitive deficits were therefore found in five of the $\mathbf{1 8}$ patients $(28 \%)$. The remaining 13 performed normally on the test battery apart from decreased verbal fluency (group 3).

Conclusions-The prevalence of cognitive impairment in MND in this population based study of an unselected cohort was higher than has been previously reported. Language deficits, especially anomia, may be relatively frequent in the MND population. Aphasia in MND may be masked by dysarthria and missed if not specifically examined.

(F Neurol Neurosurg Psychiatry 1998;65:881-889)
\end{abstract}

Department of

Neurology, Norfolk and

Norwich Health Care

NHS Trust, Norwich,

UK

W P Rakowicz

Department of

Neurology,

Addenbrooke's

Hospital and MRC

Cognition and Brain

Sciences Unit,

Cambridge, UK

W P Rakowicz

J R Hodges

Correspondence to:

Professor J R Hodges, MRC

Cambridge Cognition and

Brain Sciences Unit, 15

Chaucer Road, Cambridge

CB2 2EF, UK. Telephone

00441223 355294; fax 0044

1223359062 .

Received 6 June 1997 and in final form

21 May 1998

Accepted 15 June 1998
Keywords: motor neuron disease; dementia; aphasia

According to traditional teaching, cognitive deficits do not occur in motor neuron disease (MND; amyotrophic lateral sclerosis (ALS)). The classic picture is one of progressive loss of limb, bulbar, and respiratory muscle function caused by the selective degeneration of upper and lower motor neurons, sparing the rest of the nervous system. ${ }^{1}$ Nevertheless, there is a growing literature describing a small proportion of patients with clinically indistinguishable MND with an overt dementia or aphasic syndrome that may even precede the onset of physical symptoms. ${ }^{2}$

Drawing attention to the association of dementia and MND in the Japanese population, Mitsuyama and Takamiya suggested that this might constitute a discrete clinicopathological entity. ${ }^{3}$ Since then, an increasing number of sporadic and familial cases of dementia in the context of bulbar MND have been described in Japan. ${ }^{45}$ Similar, although predominantly sporadic, cases have subsequently been found in western countries. ${ }^{6-9}$

The most common pattern of cognitive decline in MND is a progressive dementia of the frontal lobe type. ${ }^{10}$ It is unclear whether this MND-frontal lobe dementia syndrome constitutes the extreme end of a range of disease or alternatively whether it represents a separate nosological entity. Whereas some early studies which looked for intermediate degrees of cognitive dysfunction in clinically nondemented patients with MND found no evidence of widespread impairment, ${ }^{11}$ others reported poor performance in isolated tests of memory or concentration. ${ }^{12}{ }^{13}$ The emerging picture is of consistent abnormalities on tests of so-called "frontal executive" function, most notably decreased verbal fluency, affecting a large proportion of non-demented patients with MND. These findings have been taken to indicate putative frontal lobe dysfunction, and there has been some evidence to support this from PET imaging studies. ${ }^{14-16}$ The prevalence of these cognitive abnormalities is difficult to ascertain, given the almost complete absence of prospective community based studies, but a recent hospital outpatient based study has suggested that up to a third of patients may be impaired in two or more domains of cognition. ${ }^{17}$

In addition to the MND-frontal lobe dementia syndrome, there are reports of a severe and rapidly progressive aphasia which can occur in the absence of major behavioural change. ${ }^{18} 19$ As with other cognitive deficits it is uncertain whether these cases represent a distinct subgroup as the prevalence of language impairment in MND has not been systematically studied.

The aims of our study were, therefore, to examine the prevalence of global cognitive dysfunction and more specifically language deficits in an unselected population based cohort of patients with MND. Based on our previous experience we expected to find a proportion of cases with an aphasic syndrome and wanted, in this study, to explore the question of whether they represent one end of a continuum of language deficits in MND or alternatively a distinct subgroup. A subsidiary aim was to explore the relation between bulbar dysfunction and aphasia in MND: because dysarthria and muteness have been prominent in previous cases with MND aphasia, ${ }^{18}{ }^{19}$ we hypothesised that aphasia might be overrepresented in patients with bulbar MND.

\section{Materials and methods}

SUBJECTS

The study patients were recruited from the Neurology Department of the Norfolk and 
Table 1 Basic demographic data and clinical features of patients with MND

\begin{tabular}{|c|c|c|c|c|c|c|c|c|c|c|}
\hline Patient & Age & Sex & $\begin{array}{l}\text { Education } \\
\text { (years) }\end{array}$ & $\begin{array}{l}\text { Symptom } \\
\text { duration } \\
\text { (months) }\end{array}$ & $\begin{array}{l}\text { Symptom } \\
\text { onset }\end{array}$ & Limb UMN & Limb $L M N$ & Bulbar UMN & Bulbar LMN & $\begin{array}{l}\text { Bulbar } \\
\text { score }\end{array}$ \\
\hline 1 & 48 & $M$ & 10 & 5 & $\mathrm{~L}$ & + & + & + & & 0 \\
\hline 2 & 72 & $\mathrm{~F}$ & 10 & 24 & B & + & + & + & + & $5 \mathrm{~m}$ \\
\hline 3 & 66 & F & 9 & 13 & B & & + & + & + & $5 \mathrm{~m}$ \\
\hline 4 & 75 & M & 9 & 18 & B & + & + & + & + & 3 \\
\hline 5 & 64 & M & 13 & 7 & B & + & + & + & + & 2 \\
\hline 6 & 52 & M & 10 & 20 & B & + & & + & + & $5 \mathrm{~m}$ \\
\hline 7 & 44 & M & 10 & 5 & B & + & + & & + & $6 \mathrm{~m}$ \\
\hline 8 & 75 & $\mathrm{~F}$ & 9 & 13 & B & & + & + & & $4 \mathrm{~m}$ \\
\hline 9 & 62 & M & 11 & 3 & $\mathrm{~L}$ & + & & + & + & 4 \\
\hline 10 & 74 & $\mathrm{~F}$ & 9 & 10 & B & & + & + & + & 4 \\
\hline 11 & 70 & $\mathrm{~F}$ & 9 & 13 & B & + & + & & & 3 \\
\hline 12 & 54 & $\mathrm{~F}$ & 13 & 17 & $\mathrm{~L}$ & + & + & + & & 2 \\
\hline 13 & 75 & M & 9 & 26 & $\mathrm{~L}$ & + & + & & + & 2 \\
\hline 14 & 65 & M & 9 & 12 & B & + & & + & + & 5 \\
\hline 15 & 81 & M & 9 & 6 & B & & + & + & + & 2 \\
\hline 16 & 81 & $\mathrm{~F}$ & 9 & 11 & B & + & + & & + & 5 \\
\hline 17 & 78 & $\mathrm{~F}$ & 9 & 19 & B & + & + & + & & 5 \\
\hline 18 & 75 & M & 10 & 14 & B & + & + & & + & 5 \\
\hline
\end{tabular}

Disease duration $=$ time from first symptoms to testing date.

Symptom onset: $\mathrm{B}=$ bulbar onset; $\mathrm{L}=$ limb-onset.

Examination findings: $\mathrm{UMN}=$ upper motor neuron signs; $\mathrm{LMN}=$ lower motor neuron signs; $(+)=$ present; Bulbar score $=$ dysphagia score $(0-3)+$ dysarthria score $(0-3)$ (see text); $m=$ mute.

Norwich Hospital. This is a district neurology service run by three consultant neurologists and two neurologists in training who see all outpatient and inpatient referrals to the specialty from east Norfolk and north Suffolk, a catchment area of 750 000. Patients with suspected MND are admitted as day cases for investigation, including EMG in all cases, and recorded in the database of departmental activity (MINDEX).

The study commenced in August 1995. Eleven patients with a new diagnosis of MND made between January 1994 and July 1995 were identified from the departmental database. Their inpatient and outpatient follow up files were examined for concordance with $\mathrm{El}$ Escorial research criteria for probable or definite ALS. ${ }^{1}$ A further 14 patients with a diagnosis of probable or definite ALS presented during the course of the study (August 1995 to December 1996) giving a total of 25 patients presenting between January 1994 and December 1996. The medical records were reviewed for potential causes of dementia (cerebrovascular disease, alcohol intake, serious head trauma, and significant medical conditions) but these were absent in all cases; this was later confirmed with the patients and their carers. Potential subjects were sent a written invitation to participate in the study together with a consent form.

Four of the retrospectively identified patients and three of the prospective group could not be tested: three had died, two were mute and paralysed, and two declined to be interviewed, leaving 18 study patients (10 men and eight women, mean age 67.3 (SD 11.3) years, range 44-81 years) whose clinical features are given in table 1. Fourteen patients presented with bulbar symptoms and four with limb symptoms. Five were mute at the time of testing. Testing was performed by one investigator (WR) mainly at the subjects' homes. The study was approved by the ethics committee of the Norfolk and Norwich Hospital.
CONTROLS

The performance of patients with MND was compared with that of 24 controls in the same age range selected from the MRC Applied Psychology Unit subject panel. There was no significant difference between the patients with MND and controls in terms of age (67.3 (SD 11.3) years $v 69.7$ (SD 7.8) years; NS) or educational level (9.8 (SD 1.3) years $v 10.8$ (SD 2.3) years; NS).

TESTS OF BULBAR FUNCTION

In the absence of a well validated scale of bulbar function a simple scoring system was used to assess speech and swallowing, each on a scale of 0 to 3 . The two scores were combined to give an overall "bulbar score" ranging from 0 to 6 .

Dysarthria scores $-0=$ normal speech; $1=$ slow speech, but fully intelligible; $2=$ speech intelligible only with effort; $3=$ unintelligible or mute

Dysphagia scores $-0=$ normal swallowing; $1=$ unaided swallowing, but slow or with occasional coughing or choking; $2=$ still taking food by mouth but with significant coughing, choking, or pauses between mouthfuls; $3=$ feeding via gastrostomy or nasogastric tube.

NEUROPSYCHOLOGICAL TEST BATTERY Mini mental state examination (MMSE) ${ }^{20}$

Although insensitive to frontal dysfunction, the MMSE is used routinely both clinically and in research. It is rapid to administer and gives a single score out of 30 , weighted in favour of orientation. A score $<24 / 30$ is generally taken to indicate dementia.

\section{Dementia rating scale (DRS) $)^{21}$}

The DRS is a more comprehensive cognitive screening battery consisting of five subtests (attention, initiation/perseveration, construction, conceptualisation, and memory) with a total score of 144 .

National adult reading test $(N A R T)^{22}$

The NART was used to estimate premorbid IQ. 
Digit span

Forward and reverse span were assessed according to standardised methods from the Wechsler memory scale-revised. ${ }^{23}$

Verbal fluency test ${ }^{24}$

Two versions of the verbal fluency test were used: (1) letter fluency in which subjects are asked to produce as many novel words as possible, excluding proper names, within one minute beginning with a given letter $(\mathrm{F}, \mathrm{A}$, and S). (2) Category fluency in which subjects are asked to generate words from given categories - in this case four categories of living things (animals, birds, water creatures, and dogs) and four categories of manmade items (household items, vehicles, musical instruments, and boats), in accordance with Hodges' semantic battery.

Picture naming test

The 48 item naming test, also from Hodges' semantic battery, ${ }^{25}$ consists of line drawings of 24 living and 24 manmade items matched for frequency and protypicality. No cues are given.

Graded naming test ${ }^{26}$

The graded naming test is a more stringent naming test consisting of 30 items of progressively lower frequency (for example, kangaroo, buoy, tutu).

\section{Word-picture matching test}

In this test from the semantic battery ${ }^{25}$ the subject is asked to point to successive items named by the examiner. Each target is presented in a new array consisting of eight pictures drawn from the same category (for example, land animals).

\section{Pyramids and palm trees test: three picture version $^{27}$}

In this non-verbally based test of associative semantic knowledge the subject is presented with 52 picture triads and asked to indicate which of two possible alternatives (for example, palm or fir tree) is associated with the target (pyramid).

Test for the reception of grammar (TROG) ${ }^{28}$ The TROG was designed to assess syntactical aspects of language in children using high frequency vocabulary. The subject points to the one picture out of four which corresponds to a sentence read by the examiner. There is a total of 80 trials which progress from simple (for example, plural, gender) to more complex grammatical structures (for example, embedded clauses, reversible passive).

\section{TESTS OF MOOD AND INFORMANT INTERVIEW} Hospital anxiety and depression scale $(H A D S)^{29}$ All subjects were asked to complete the HADS at the end of the interview. Fourteen questions assess the subjects' reported mood over the past week. Symptoms related to anxiety and depression are scored up to a possible total of 21 for each.

Where possible a third party was interviewed separately from the subject and then asked to complete the following questionnaire:
Clinical dementia rating $(C D R)^{30}$

Informants were asked to judge the subject's optimal performance in memory, orientation, decision making, and activities of daily living based on standardised descriptions, and using a scale of $0,0.5,1.0,2.0$, and 3.0 points, corresponding to normal, questionable, mild, moderate, and severe impairment. A composite score was then derived ranging from 0 or 0.5 (no or questionable dementia) to 3.0 (severe dementia).

\section{ANALYSES}

It is recognised that due to small numbers the power of this study is low, but it is based on the maximum available data. These were analysed both in terms of group and individual scores. Differences in parametrically distributed variables between subject and control groups were analysed using Student's $t$ test for unpaired variables (age, education, NART, digit span, verbal fluency, and graded naming test). Nonparametrically distributed variables were analysed using the Mann-Whitney $U$ test (MMSE, DRS, picture naming, word-picture matching, pyramids and palm trees test, TROG). Tests were considered significant at the $5 \%$ level. However, $\mathrm{p}$ values approaching significance (below the 10\% level) are also shown because they may indicate an association that in a larger study would reach the conventional $5 \%$ level of significance.

Where relevant, the performance of individuals was compared against population normative data using $z$ scores. This is effectively a "cut-off" method similar to that applied in standard clinical practice, in which an abnormal result is one falling 2 or more SD below the control group mean $(z>2)$. To examine the relation between bulbar symptoms and the presence of dementia and aphasia we calculated Spearman rank correlation coefficients comparing firstly the dysarthria score and then the total bulbar score to performance on MMSE, DRS, picture naming, and GNT.

\section{Results}

The full neuropsychological battery was administered to all subjects who were able to speak. Five mute patients were unable to have their NART IQ and verbal fluency assessed. Moreover, one of these (patient 3) was so demented that she was unable to complete even tests for which no verbal response was required.

GENERAL CHARACTERISTICS

Overall the differences between mean group performance of the patient cohort and controls was small. There was a consistent and significant reduction in verbal fluency and reverse digit span in the patient group (table 2). Small differences in group mean scores also reached significance on the dementia rating scale, pyramids and palm trees test, and TROG. The differences in performance of the patient group on the mini mental state examination and graded naming test reached significance at the $\mathrm{p}<0.1$ level. There was no 
Table 2 Mean neuropsychological test scores in patients with MND and controls

\begin{tabular}{|c|c|c|c|c|c|c|c|}
\hline & \multicolumn{3}{|c|}{ Patients with $M N D$} & \multicolumn{3}{|l|}{ Controls } & \multirow[b]{2}{*}{ p Value } \\
\hline & Mean & $S D$ & $n$ & Mean & $S D$ & $n$ & \\
\hline Age (y) & 67.3 & 11.3 & 18 & 69.7 & 7.8 & 24 & NS \\
\hline Education (y) & 9.8 & 1.3 & 18 & 10.8 & 2.3 & 24 & NS \\
\hline NART I.Q. & 106.5 & 8.6 & 13 & 109.9 & 6.2 & 24 & NS \\
\hline \multicolumn{8}{|l|}{ Digit span: } \\
\hline Forwards & 6.4 & 1.1 & 17 & 6.8 & 1.0 & 24 & NS \\
\hline Reverse & 3.8 & 1.0 & 17 & 4.8 & 1.2 & 24 & $\mathrm{p}<0.05$ \\
\hline \multicolumn{8}{|l|}{ Verbal fluency: } \\
\hline Letters & 25.1 & 11.5 & 13 & 45.2 & 9.9 & 24 & $\mathrm{p}<0.005$ \\
\hline Categories & 91.5 & 30.4 & 13 & 113.7 & 19.4 & 24 & $\mathrm{p}<0.05$ \\
\hline \multirow[t]{2}{*}{ Graded naming test } & 18.6 & 6.9 & 17 & 22.5 & 4.3 & 24 & $\mathrm{p}<0.1$ \\
\hline & Median & Range & $n$ & Median & Range & $n$ & $p$ Value \\
\hline MMSE & 29 & $19-30$ & 17 & 29.5 & $27-30$ & 24 & $\mathrm{p}<0.1$ \\
\hline Dementia rating scale & 139 & $100-144$ & 17 & 141 & $135-144$ & 24 & $\mathrm{p}<0.05$ \\
\hline Clinical dementia rating & 0 & $0-2$ & 18 & - & - & - & - \\
\hline Picture naming & 46 & $32-48$ & 17 & 43.5 & $38-47$ & 24 & NS \\
\hline Word-picture matching & 48 & $44-48$ & 17 & 48 & $44-48$ & 24 & NS \\
\hline Pyramids and palm trees & 50 & $44-52$ & 17 & 52 & $46-52$ & 24 & $\mathrm{p}<0.05$ \\
\hline TROG & 78 & $59-80$ & 17 & 80 & $73-80$ & 24 & $\mathrm{p}<0.05$ \\
\hline
\end{tabular}

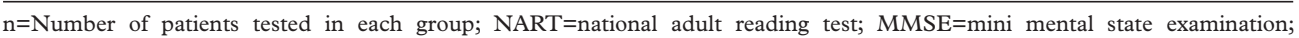
TROG=test for the reception of grammar; median scores and ranges are given for data that are not normally distributed.

demonstrable difference between patients and control subjects on NART IQ, forward digit span, picture naming, and word-picture matching.

The patients were divided for analysis purposes into three subgroups (table 3). Five patients $(5 / 18,28 \%)$ showed clear evidence of language impairment. We have distinguished those who were demented (3/18: group 1) from those in whom language problems were the only demonstrable cognitive abnormality (2/ 18: group 2). One patient in group 1 (patient 3) was too demented to complete the formal test battery. The remainder (group 3) constituted those patients (13/18) who performed within normal limits on the full battery of general and language tasks other than verbal fluency (discussed below). Those with a borderline abnormal score on just one component of the language battery were included in group 3 .
BULBAR SYMPTOMS

Thirteen subjects had bulbar onset disease but at the time of testing virtually all had some degree of bulbar involvement on objective assessment (median bulbar score $=4$; range $0-6)$. Five subjects were mute at the time of testing and were unable to execute those tasks completely dependent on a verbal response (NART and verbal fluency) but completed the spoken components of other tasks with written responses.

There was no significant correlation between either the dysarthria score or the total bulbar score and MMSE, DRS, picture naming, or GNT ( $\mathrm{p}$ values ranging from 0.293 to 0.876 ).

TESTS OF GENERAL COGNITIVE FUNCTION

Global dementia

Global cognitive function as judged by MMSE showed some evidence of possible impairment

Table 3 Individual neuropsychological test scores in patients with MND

\begin{tabular}{|c|c|c|c|c|c|c|c|c|c|c|c|c|c|c|}
\hline Patient & $\begin{array}{l}\text { Dysarthria } \\
\text { score }\end{array}$ & $\begin{array}{l}\text { NART } \\
I Q\end{array}$ & MMSE & $\begin{array}{l}\text { Dementia } \\
\text { rating } \\
\text { scale }\end{array}$ & $\begin{array}{l}\text { Clinical } \\
\text { dementia } \\
\text { rating }\end{array}$ & $\begin{array}{l}\text { Digit span } \\
\text { forwards }\end{array}$ & $\begin{array}{l}\text { Digit } \\
\text { span- } \\
\text { reverse }\end{array}$ & $\begin{array}{l}\text { Verbal } \\
\text { fluency- } \\
\text { letters }\end{array}$ & $\begin{array}{l}\text { Verbal } \\
\text { fluency- } \\
\text { categories }\end{array}$ & $\begin{array}{l}\text { Picture } \\
\text { naming }\end{array}$ & $\begin{array}{l}\text { Graded } \\
\text { naming } \\
\text { test }\end{array}$ & $\begin{array}{l}\text { Word- } \\
\text { picture } \\
\text { matching }\end{array}$ & $\begin{array}{l}\text { Pyramids } \\
\text { and palm } \\
\text { trees }\end{array}$ & TROG \\
\hline \multicolumn{15}{|c|}{ Group $1 \mathrm{MND}$ with dementia and aphasia: } \\
\hline 1 & 0 & 96 & $21^{\star}$ & $107^{\star}$ & 1 & 5 & 3 & $10^{\star}$ & $35^{\star}$ & $43^{\star}$ & $10^{\star}$ & $44^{\star}$ & $48^{\star}$ & $63^{\star}$ \\
\hline 2 & $3 \mathrm{~m}$ & NA & $19^{\star}$ & $100^{\star}$ & 1 & 5 & $2^{\star}$ & NA & NA & $32^{\star}$ & $9^{\star}$ & $45^{\star}$ & $44^{\star}$ & $59^{\star}$ \\
\hline 3 & $3 \mathrm{~m}$ & NA & NA & NA & 2 & NA & NA & NA & NA & $\mathrm{NA} \dagger$ & $\mathrm{NA} \dagger$ & NA & NA & NA \\
\hline \multicolumn{15}{|c|}{ Group 2 MND with aphasia: } \\
\hline 4 & 2 & 98 & 30 & 138 & 0 & 6 & 3 & $11^{\star}$ & $64^{\star}$ & $35^{\star}$ & $7^{\star}$ & $44^{\star}$ & $48^{\star}$ & 78 \\
\hline 5 & 1 & 120 & 29 & 136 & 0 & 7 & 5 & $24^{\star}$ & 89 & $32^{\star}$ & $11^{\star}$ & 48 & 51 & $74^{\star}$ \\
\hline \multicolumn{15}{|c|}{ Group 3 MND without dementia or aphasia: } \\
\hline 6 & $3 \mathrm{~m}$ & NA & 28 & 139 & 0 & 6 & 3 & NA & NA & 48 & 19 & 48 & 52 & 77 \\
\hline 7 & $3 \mathrm{~m}$ & NA & 29 & 140 & 0 & 7 & 4 & NA & NA & 48 & 28 & 48 & 51 & 80 \\
\hline 8 & $3 \mathrm{~m}$ & NA & 30 & 137 & 0 & 6 & 4 & NA & NA & 48 & 18 & 48 & 49 & 80 \\
\hline 9 & 2 & 114 & 30 & 143 & 0 & 8 & 4 & 41 & 127 & 48 & 27 & 48 & 51 & 79 \\
\hline 10 & 2 & 103 & 29 & 139 & 0 & 7 & 3 & 34 & 86 & 46 & 19 & 48 & 50 & 78 \\
\hline 11 & 2 & 102 & 28 & 136 & 0 & 6 & 4 & $19^{\star}$ & 83 & 46 & 18 & 48 & 49 & 80 \\
\hline 12 & 1 & 122 & 29 & 144 & 0 & 7 & 5 & $23^{\star}$ & 159 & 48 & 30 & 48 & 52 & 80 \\
\hline 13 & 1 & 114 & 30 & 140 & 0.5 & 8 & 5 & 36 & 103 & 48 & 28 & 48 & 51 & 78 \\
\hline 14 & 2 & 96 & 27 & 140 & 0 & 5 & 3 & $17^{\star}$ & $68^{\star}$ & 46 & 17 & 48 & 52 & 76 \\
\hline 15 & 2 & 105 & 28 & 130 & 0 & 5 & 4 & $8^{\star}$ & $79^{\star}$ & $42^{\star}$ & 20 & 47 & 49 & 75 \\
\hline 16 & 2 & 103 & 27 & 140 & 0 & 8 & 6 & 29 & 89 & 48 & 21 & 48 & $48^{\star}$ & 77 \\
\hline 17 & 2 & 103 & 30 & 140 & 0 & 6 & 4 & 37 & 98 & $42^{\star}$ & 14 & 47 & 52 & 78 \\
\hline 18 & 2 & 108 & 26 & 137 & 0 & 6 & 3 & 37 & 109 & 47 & 20 & 48 & $48^{\star}$ & 77 \\
\hline Max & 3 & 130 & 30 & 144 & 3 & & & & & 48 & 30 & 48 & 52 & 80 \\
\hline
\end{tabular}

$\star=$ Score outside normal range $(z>2)$; max=maximum possible score on given test.

Dysarthria score: $0=$ normal speech; 1 =slow speech but fully intelligible; $2=$ intelligible only with effort; $3=$ unintelligible or mute ( $\mathrm{m}$ );

NA=subject unable to perform test: mute patients were unable to perform the NART and verbal fluency tasks;

$\mathrm{NA} \dagger=$ patient 3 too demented to complete full battery but showed severe naming deficits with written responses.

$\mathrm{NART}=$ national adult reading test; $M M S E=$ mini mental state examination; $T R O G=$ test for the reception of grammar. 
(median score (range), patients with MND 29 (19-30) $v$ controls $29.5(27-30) ; 0.1>\mathrm{p}>0.05)$. The difference in performance in the DRS, however, reached significance (median score (range), patients with MND 139 (100-144) v controls $141 \quad(135-144) ; \mathrm{p}<0.05)$. When looked at individually, three patients (group 1) were clearly demented on formal testing (MMSE<24/30), witness interview (CDR $>0.5)$, or both; their clinical presentation is detailed in the case histories below. In summary, patient 1 presented with a change in behaviour and personality consistent with a frontal lobe dementia. Patients 2 and 3 had an aphasic onset dementia, with initially good preservation of personality and behaviour. All three demented patients performed poorly on tests of naming and comprehension.

Digit span

Mean group digit spans forward were not significantly different from controls (6.4 (SD 1.1) v 6.8 (SD 1.0); NS). Reverse digit span, however, was significantly reduced in the MND patient group (3.8 (SD 1.0) $v 4.8$ (SD $1.2), \mathrm{p}<0.05)$.

\section{Verbal fluency}

Five patients were unable to perform this test due to mutism. There was, however, a significant difference between the remaining 13 patients and the control group on verbal fluency (letter fluency 25.1 (SD 11.5) v 45.2 (SD 9.9), p<0.005; category fluency: 91.5 (SD 30.4) $v 113.7$ (SD 19.4), $\mathrm{p}<0.05$ ). When analysed according to individual patients' scores, seven of the 13 patients able to perform the tests showed impairment in letter fluency. Category fluency was defective in four of these patients but was never affected in patients with normal letter fluency. Four patients $(11,12,14$, and 15) had reduced verbal fluency as the only abnormal finding with otherwise normal performance on general and language tests.

\section{LANGUAGE TESTS}

Significant language deficits were found in the three demented patients (group 1) and two non-demented patients (group 2). The demented patients performed poorly in all language tests, but particularly in tests of naming and syntactic comprehension (TROG). The non-demented patients had a language output disorder characterised by difficulties with word finding and naming, with a tendency to make category-coordinate semantic errors or circumlocutions. Both performed well on tests of non-verbal semantic knowledge and grammar. Repetition, as judged by the registration component of the MMSE, was unaffected with all test subjects repeating all three items on immediate recall. A few otherwise unaffected patients performed just outside the normal range on single components of the language battery and were included in the non-demented, non-aphasic group (group 3). We now describe the performance on each of the tests.

\section{Naming}

The performance of patients was comparable with controls on the picture naming (median score (range), patients with MND 46 (32-48); controls 43.5 (38-47); NS) but there was a possible impairment on the graded naming test (18.6 (SD 6.9) $v 22.5$ (SD 4.3), 0.1 >p >0.05). The five patients in groups 1 and 2 were clearly distinguishable from the rest of the patient population by the presence of word finding difficulties and anomia (patient 3 had no verbal output but her written naming was very impaired-see case histories below). Difficulties were encountered on both the easier picture naming task and the more stringent graded naming test. Errors tended to be semantic rather than phonological (for example, "cupboard" for "refrigerator"; "rabbit" for "squirrel"), often preceded by a pause or an attempt to describe the object (for example, sledge: “...board for snow...skateboard.") although there was also a tendency to perseverative responses in the demented patients. Patient 4 showed a degree of category specificity with many more errors on living creatures (11/24) than on manmade items $(2 / 24)$; this pattern was also present on the respective word-picture matching subtests (see below). The remaining 13 patients (group 3) performed normally on both naming tests.

\section{Word-picture matching test}

Of the four patients in groups 1 and 2 able to complete this test, three had scores below the normal range, although the level of impairment was mild. Patient 4 had difficulties confined to identifying living creatures (4/24 errors), scoring well on manmade items ( $0 / 24$ errors), mirroring a degree of category specificity seen in his naming deficit (see above). All patients in group 3 performed normally and the mean performance of the patient group as a whole was not significantly different from controls (median score (range), patients with MND 48 (44-48) $v$ controls 48 (44-48); NS).

Pyramids and palm trees test

Low scores were seen in the two demented patients able to complete the test and one of the aphasic patients. The remaining 14 nondemented patients able to complete the test performed normally, but the difference in mean performance was lower than controls and this reached significance (median score (range), patients with MND 50 (44-52) $v$ controls $52(46-52) ; \mathrm{p}<0.05)$.

\section{TROG}

Both of the demented patients ( 1 and 2 ) who were able to complete this test had very low scores ( $z=-8.3$ and -10.4 respectively). One aphasic patient (5) had a borderline low score but the remainder of the patient population performed normally. Once again, the difference in performance between the patient and control groups reached significance (median score (range), patients with MND 78 (59-80) $v$ controls 80 (73-80); $\mathrm{p}<0.05)$. 
TESTS OF MOOD AND INFORMANT INTERVIEW Hospital anxiety and depression score

All patients had low scores for both anxiety and depression (mean scores $=6.9$ (SD 2.1) and 5.1 (SD 2.0) respectively) suggesting that affective states were unlikely to be influencing performance.

Clinical dementia rating and informant interview Impaired performance on everyday cognitive tasks and activities of daily life (CDR $>0.5)$ was reported in all three demented patients (group 1 ). This corroborated the MMSE scores in the mild to moderate dementia range achieved by the two members of the group who were sufficiently intact for formal testing. Carers did not report abnormal cognition or behaviour in patients in group 3 who performed normally on tests other than verbal fluency. Normal behaviour was also reported in the two aphasic patients (group 2) although one of the informants volunteered and the other admitted on direct questioning that their spouses had word finding and naming difficulties.

\section{Case histories}

PATIENT 1

A 48 year old man presented with a 6 month complaint of "slowed thinking" and sleep disturbance. His wife reported vagueness at work, lability of mood, and memory disturbance. He had been forced to stop using his car after driving on the wrong side of the road.

On examination he had a rather facile affect, a mild spastic dysarthria, fasciculations in all four limbs with brisk reflexes, and extensor plantar responses.

Cognitive testing disclosed a mild dementia (MMSE $=21 / 30)$ with impairment on tests of attention and concentration, abstract thinking, memory, and language (DRS $=107 / 144)$. Performance was at the lower limit of normal in all subtests of the semantic battery, but was particularly impaired in verbal fluency (FAS $=10$ ), naming (picture naming $=43 / 48$; graded naming test $=10 / 30)$, and syntactic comprehension (TROG=63/72). Naming errors consisted of semantic paraphasias, many of his descriptions suggesting relative sparing of semantic knowledge (for example, accordion: "one you play ... harpsichord"; bellows: "for blowing ... forge").

PATIENT 2

A 72 year old woman began slurring her speech 2 years before presentation to a neurologist. Over 6 months her speech became barely intelligible although she continued to use complete sentences. Over the next 6 months her verbal output decreased further, initially to single appropriate words and finally to mutism a year after symptom onset. She communicated with ease using pen and paper. Eighteen months after onset she began to experience difficulties with swallowing fluids and at the time of presentation also had some problems with solids.

Examination showed a woman with a labile affect and a tendency to grin incongruously. There was a mixed bulbar and pseudobulbar palsy, widespread fasciculations in the upper limbs, hyperreflexia in all four limbs, but flexor plantar responses.

Cognitive testing disclosed a mild dementia (MMSE=19/30; DRS 100/144), naming difficulties (picture naming $=32 / 48$; graded naming test $=9 / 30$ ), and errors on tests of syntax (TROG=59/72). Her anomia consisted predominantly of semantic paraphasias but there were also extensive spelling errors and a tendency to perseverative responses.

PATIENT 3

A 66 year old woman began to make semantic paraphasic errors in spontaneous speech 1 year before presentation. Over a 4 month period her speech output reduced drastically to monosyllabic answers. Six months into the illness she became mute, but was able to communicate using her hands, and to answer questions on the telephone by tapping the receiver to indicate yes or no answers. Eight months after onset she began to have difficulty swallowing and stopped taking solids. Shortly afterwards she started to make mistakes while cooking but initially continued to live independently. Admission was precipitated after she had failed to contact the family; she was found in the bath in a state of evident self neglect.

Examination disclosed a mute woman, capable of producing only occasional incomprehensible groans. The tongue was wasted and fasciculating, the jaw jerk brisk with spontaneous clonus. There were fasciculations in all four limbs with brisk reflexes and extensor plantar responses. Pout, palmomental, and grasp reflexes were elicited.

She was able to follow simple one step instructions but failed with two stage commands and was unable to cooperate with the examination, which seemed to baffle her. Her spontaneous written repertoire was limited to her own name and a few simple words. She only attempted to write the names of a few line drawings and her responses were incorrect, mis-spelt, and perseverative. She displayed utilisation behaviour, repeatedly "emptying" an empty glass.

\section{PATIENT 4}

A 75 year old man presented to the ear, nose, and throat surgeons with bouts of coughing after drinking and eating, trouble with singing, and progressive slurring of speech over 6 months. A year later his speech and swallowing had deteriorated with particular dysphagia for thin liquids and he complained of difficulties with using his left hand and of night cramps. $\mathrm{He}$ also reported word finding difficulties such that he had stopped public speaking. When specifically asked, his wife admitted that he would often hesitate in midsentence, often substituting an incorrect word for one that he was unable to recall.

Neurological review disclosed slow tongue movements with occasional fasciculations, some frontal release signs, but a normal jaw jerk. Limb examination showed widespread wasting and fasciculations, normal tone, but hyperreflexia with extensor plantar responses. 
Performance on general cognitive tests was normal but he showed impairment in verbal fluency (FAS $=11$ ) and on the naming components (picture naming $=35 / 48$; graded naming test $=7 / 30$ ) of the language battery. He had particular difficulties with naming living creatures (13/24 correct) compared with manmade items $(22 / 24)$. His performance was also below the normal range on word-picture matching (44/ 48 ), with errors confined to identifying living creatures, and just outside normal limits on the pyramids and palm trees test.

PATIENT 5

A 64 year old man presented with a 6 month history of slurred speech, occasional dysphagia, and twitching and cramps in the lower limb muscles. His wife had noticed the occasional substitution of incorrect words in a sentence although he continued to teach.

Examination showed a mild dysarthria with slow tongue movements but no fasciculations. There were extensive fasciculations in all four limbs with brisk deep tendon reflexes and extensor plantar responses.

General cognitive function was unimpaired and decreased verbal fluency was confined to letter fluency. His performance on the test for the reception of grammar was just outside normal limits (74/80) and he was significantly impaired in naming tasks (picture naming $=32$ / 48; graded naming test $=11 / 30$ ) with a mixture of semantic errors and "don't know" responses.

\section{Discussion}

We have systematically tested language and general cognition in 18 patients with a new diagnosis of sporadic MND presenting consecutively over a 3 year period to a regional neurology service. This unselected cohort contains a surprisingly high number of subjects $(5 / 18,28 \%)$ with a language disorder; three (group 1) in the context of a dementing illness and two (group 2) in whom aphasia was the only demonstrable cognitive deficit. The remaining patients (13/18, 72\%: group 3) performed normally in the language tasks although many had low scores on a test sensitive to frontal executive dysfunction (verbal fluency).

DEMENTIA AND MND

The association between overt dementia and MND is now well recognised re $^{2-9}$ but has always been considered to represent a rare co-occurrence. Two large retrospective epidemiological studies have reported the presence of unspecified dementia in $4 \%$ and $6 \%$ of patients with $\mathrm{MND},{ }^{32}{ }^{33}$ whereas two smaller prospective studies did not identify any demented patients. ${ }^{12}{ }^{14}$ Likewise, a large recent study of 146 patients under follow up by a specialist MND outpatient service seemed not to report any frankly demented patients despite finding evidence of more subtle cognitive impairment on neuropsychological assessment in a third of cases. ${ }^{17}$

We were surprised to find such a high prevalence of overt dementia (3/18) in our MND cohort. In addition, whereas the group as a whole performed within normal limits on the MMSE (median score (range), patients with MND 29 (19-30) $v$ controls 29.5 (27-30); $0.1>p>0.05)$. the magnitude of the difference from controls on the DRS reached significance (median score (range), patients with MND 139 (100-144) $v$ controls 141 (135-144); $\mathrm{p}<0.05)$. The geographical isolation of the region served by one neurology department makes it unlikely that subjects with MND were missed and the population based nature of our study minimised the risk of selection bias. We identified 25 patients with a new diagnosis of MND over a 3 year period (January 1994 to December 1996) from a catchment area of about 750000 , equivalent to an annual incidence rate of 1.1 per 100000 population. This is similar to the rates reported in previous epidemiological surveys $(2.0-2.2 \text { per } 100000)^{34} 35$; some of the difference is explained by the application of stricter El Escorial criteria which had not been established at the time of the earlier studies. We were able to test 18 of the 25 patients identified. Even if the remaining seven patients unavailable for testing were normal, then the prevalence of significant dementia in this population would be $3 / 25(12 \%)$, which is greater than previously reported. Finally, the mean age of our group was 67.3 (SD 11.3) years which is at the upper end of the normally quoted range of onset of sporadic MND (55 to 65 years). ${ }^{36}$ This could potentially affect the incidence of dementia in this group, but none of the patients presented with an amnestic syndrome, which would be more suggestive of Alzheimer's disease. The few patients involved means that epidemiological conclusions should be drawn with caution but our findings do suggest that the problem may be underestimated in clinical practice. The common assumption that cognitive function is not impaired in MND, which holds true for most patients, may tempt physicians to underdiagnose the condition on the grounds that impaired patients will "by definition" not have MND.

The pattern of cognitive loss in the three demented patients (group 1) was broadly in line with previous reports. One of the three matched the MND frontal lobe dementia syndrome with behavioural change being a prominent part of the presenting picture ${ }^{10}$ but was unusual in having significant language deficits. Two were more similar to the MND-rapidly progressive aphasia syndrome which has only been recognised more recently, with an early loss of language in the context of bulbar onset disease and relative preservation of other cognitive abilities in the early stages. ${ }^{18} 19$

LANGUAGE IMPAIRMENT IN MND

No epidemiological data are available on the prevalence of progressive aphasia in MND. ${ }^{18} 19$ In our study we have distinguished two types of patients with aphasic MND. The first (three patients in group 1) had a mixed aphasiadementia syndrome whereas the second (two patients in group 2) had a pure aphasia. It is possible that the "pure aphasia" we have shown represents the first stages of an aphasic- 
dementing process rather than a mild and relatively stable subclinical abnormality. This could be considered in a follow up study.

The nature of the language impairment in MND seems not to be uniform but impaired naming and syntactic comprehension have been noted regularly. We have found an anomia in demented patients and, in addition, the group tended to perform worse than controls on the more stringent of the two naming tests, the graded naming test (18.6 (SD 6.9) $v 22.5$ (SD 4.3$) ; 0.1>p>0.05$ ). Although not assessed separately, all patients scored $3 / 3$ on the repetition component of the MMSE. Of our three demented patients (group 1) two were able to undergo formal testing and demonstrated impaired picture naming and syntax comprehension (TROG). Semantic knowledge as judged by the word-picture matching and pyramids and palm trees tests (tables 2 and 3) was relatively spared although the scores were low, the difference reaching significance on the last test (median score (range), patients with MND 50 (44-52) v controls 52 (46-52); $\mathrm{p}<0.05)$. Interestingly, the deficit was similar in patient 2, who presented with a fairly pure aphasic type dementia, and in patient 1 who displayed features more consistent with a frontal lobe type dementia. The two patients also differed in bulbar involvement and muteness, patient 2 being mute (bulbar score=5), but patient 1 being asymptomatic with only mild signs of a pseudobulbar palsy evident on examination (bulbar score $=0$ ). Although unable to complete the formal language battery, the third patient in this group (patient 3) had severe comprehension difficulties limited to carrying out simple one stage commands, made perseverative and spelling errors on writing, and was mute. The two non-demented patients with language impairment (group 2) showed cognitive deficits affecting language only, but over and above the decreased verbal fluency discussed below. The pattern was of a predominant anomia (with poor performance on naming tests) but one patient was also mildly impaired on tests of single word comprehension whereas the other was below the normal range on the test of syntactic comprehension (TROG).

\section{MILDER FORMS OF COGNITIVE IMPAIRMENT IN} MND

There has been a divergence of opinion between investigators about the presence and nature of subclinical cognitive impairment in patients with MND. One group has reported completely normal cognitive function in MND both on initial assessment and at subsequent follow up. ${ }^{11}$ Several investigators have found consistent subtle abnormalities largely confined to impairment in tests of fluency and concentration. ${ }^{12-16}$ These deficits have been ascribed to mild frontal executive dysfunction and a correlation with reduced blood flow to the frontal lobes on PET has been described. ${ }^{14-16}$

The deliberate bias towards language impairment of our study limited the number of tests specifically considering frontal lobe func- tion. Nevertheless our finding of decreased verbal fluency in the MND patient population replicates the findings of other investigators and was seen in demented and undemented patients alike. The fact that both letter and category based fluency were affected suggests that the deficit was one of executive function, of the type seen in patients with frontal or subcortical pathology rather than reflecting semantic impairment which results in a disproportionate reduction in category fluency. ${ }^{37}$

As with MND dementia, the frequency of subtle cognitive deficits in the MND population is difficult to judge from the literature. We have identified 5/18 (28\%) patients with dementia, or aphasia, or both. If the four patients in group 3 with decreased verbal fluency as the only cognitive deficit are included, the number in our patient group with demonstrably impaired cognition rises to $9 / 18(50 \%)$. Only two prospective neuropsychological studies have previously been reported. ${ }^{12} 14$ Although both have found that the mean patient group performance on tests of attention and concentration was significantly worse than controls, only one quotes individual patient performances with 8/14 (57\%) patients failing the Wisconsin card sorting test. The largest neuropsychological study to date of 146 patients attending a dedicated MND clinic has suggested that as many as $35 \%$ of patients have significant impairment, performing at or below the 5 th percentile on at least two of eight neuropsychological measures. ${ }^{17}$ Unfortunately, this study was not prospective and the selected nature of the group raises the possibility that their performance may not be representative of the MND population as a whole; whereas the incidence of cognitive decline was high, there were apparently no formally demented patients.

Previous neuropsychological studies have not reported prominent language deficits in non-demented patients. This may be because they have typically concentrated on tests of frontal lobe dysfunction and memory. Massman et al report $11.7 \%$ of their patients at or below the 5 th percentile on the Boston naming test. ${ }^{17}$ All the same, our finding of two non-demented patients with significant naming problems on formal testing suggests that there may be a subgroup of patients with MND with aphasia who would be missed on cursory bedside cognitive assessments or even on more detailed testing if language tests were not specifically included.

BULBAR FUNCTION AND DEMENTIA IN MND Many authors have commented on an association between cognitive impairment and bulbar disease in MND. ${ }^{18} 1931$ A recent study specifically looking into this issue in patients attending a specialist MND clinic found a significant increase in cognitive dysfunction in patients with a pseudobulbar palsy compared with those without, although both groups were impaired. ${ }^{38}$

Formal statistical testing of our cohort failed to show such a correlation although we recognise that our sample is small. Two of the three demented patients in group 1 and one of the 
aphasic patients in group 2 had significant bulbar dysfunction and broadly fitted the previously described picture of dementia/aphasia in the context of bulbar onset disease. Two patients with minimal bulbar involvement, however, showed clear cut cognitive decline: one with a moderately severe aphasic dementia (patient 1), the other with aphasia only (patient 5). This shows that cognitive dysfunction is not confined to patients with bulbar onset or severe bulbar disease. Taken together these findings would also suggest that cognitive decline is not simply an indicator of disease severity.

The fact that two of the three demented patients were also mute does raise the practical question of whether cognitive and language impairment may be missed in such patients. Both carers and professionals tend to attribute mutism to purely motor problems in MND and usually fail to assess language adequately. The recognition of additional language impairment is clearly important for the appropriate management of such patients.

We thank Dr David Dick and all the members of the Neurology Department at the Norfolk and Norwich NHS Trust for their assistance, Dr German Berrios, Rose Ward, and Naida Graham for advice, and Mrs Sally Lincoln and Mrs Mary Phillips for their secretarial support. We have received no external funding for this research. This work was presented at the joint meeting of the Australian Association of Neurologists and the Association of British Neurologists, Sydney, May 1997.

1 World Federation of Neurology Research Group on Neuromuscular Diseases. El Escorial World Federation of Neurology criteria for the diagnosis of amyotrophic lateral sclerosis. F Neurol Sci 1994;124(suppl): 96-107.

2 Kew J, Leigh N. Dementia with motor neuron disease. Baillieres Clin Neurol 1992;1:611-26.

3 Mitsuyama Y, Takamiya S. Presenile dementia with motor neuron disease in Japan: a new entity? Arch Neurol 1979;36:592-3.

4 Yoshida M, Murakami N, Hashizume Y, et al. A clinicopathological study on 13 cases of motor neuron disease with dementia. Clin Neurol 1992;32:1193-202.

5 Mitsuyama Y. Presenile dementia with motor neuron disease. Dementia 1993;4:137-42. 6 Wikstrom J, Paetau A, Palo J, et al. Classic amyotrophic lat-
eral sclerosis with dementia. Arch Neurol 1982;39:681-3. 7 Neary D, Snowden JS, Mann DMA, et al. Frontal lobe Neary D, Snowden JS, Mann DMA, et al. Frontal lobe
dementia and motor neuron disease. $f$ Neurol Neurosurg Pementia and motor neuron

8 Lopez OL, Becker JT, De Kosky ST. Dementia accompanying motor neuron disease. Dementia 1994;5:42-7.

9 Gunnarsson LG, Dahlbom K, Strandman E. Motor neuron disease and dementia reported among 13 members of a single family. Acta Neurol Scand 1991;84:429-33.

10 Neary D, Snowden JS, Mann DMA. The clinical pathological correlates of lobar atrophy. Dementia 1993;4:154-9.

11 Capitani E, Della Salla S, Marchetti C. Is there a cognitive impairment in MND? A survey with longitudinal data. Schweiz Arch Neurol Psychiatr 1994;145:11-13.

12 David AS, Gillham RA. Neuropsychological study of motor neuron disease. Psychosomatics 1986;27:441-5.
13 Gallassi R, Montagna P, Morreale A, et al. Neuropsychological, electroencephalogram and brain computed tomography findings in

14 Ludolph AC, Langen KJ, Regard M, et al. Frontal lobe function in amyotrophic lateral sclerosis: a neuropsychologic and positron emission study. Acta Neurol Scand 1992; 85:81-9.

15 Kew JJM, Leigh PN, Playford ED, et al. Cortical function in amyotrophic lateral sclerosis: a positron emission tomography study. Brain 1993;116:655-80.

16 Kew JJM, Goldstein LH, Leigh PN, et al. The relationship between abnormalities of cognitive function and cerebral activation in amyotrophic lateral sclerosis. Brain 1993;116: 1399-423.

17 Massman PJ, Sims J, Cooke N, et al. Prevalence and correates of neuropsychological deficits in amyotrophic latera sclerosis. F Neurol Neurosurg Psychiatry 1996;61:450-5.

18 Caselli FJ, Windebank AJ, Peterson RC, et al. Rapidly progressive aphasic dementia and motor neuron disease. Ann Neurol 1993;33:200-7.

19 Doran M, Xuereb J, Hodges JR. Rapidly progressive aphasia with bulbar motor neuron disease: a clinical and neuropsychological study. Behavioural Neurology 1995;8:169-80.

20 Folstein MF, Folstein SE, McHugh PR. Mini-mental state: a practical guide for grading the mental state of patients for the clinician. F Psychiatr Res 1975;12:189-98.

21 Mattis S. Dementia rating scale. Odessa, FL: Psychological Assessment Resources, 1988.

22 Nelson HE. National adult reading test. Windsor, Berkshire, UK: NFER-NELSON, 1978.

23 Wechsler D. Wechsler adult intelligence scale-revised. San Antonio: The Psychological Corporation, 1987.

24 Benton AL, Hamsher KdeS. Multilingual aphasia examination. Iowa City, IA: University of Iowa, 1976.

25 Hodges JR, Salmon DP, Butters N. The nature of the naming deficit in Alzheimer's and Huntington's disease. Brain 1991;114:1547-58.

26 McKenna P, Warrington EK. Graded naming test. Windsor, Berkshire, UK: NFER-NELSON, 1983.

27 Howard D, Patterson K. Pyramids and palm trees: a test of semantic access from pictures and words. Bury St Edmunds, UK: Thames Valley, 1992.

28 Bishop DVM. Test for the reception of grammar. Manchester, UK: University of Manchester, 1983.

29 Zigmond AS, Snaith RP. The hospital anxiety and depression scale. Acta Psychiatr Scand 1983;67:361-70.

30 Berg L. Clinical dementia rating scale (CDR). Psychopharmacol Bull 1988;24:637-9.

31 Hudson AJ. Amyotrophic lateral sclerosis and its association with dementia, parkinsonism and other neurological disorders: a review. Brain 1981;104:217-47.

32 Kondo K, Hemmi I. Clinical statistics in 515 fatal cases of motor neuron disease: determinants of course. Neuroepidemiology 1984;3:129-48.

33 Gubbay SS, Kahan E, Zilber N, et al. Amyotrophic lateral sclerosis: a study of its presentation and prognosis. 7 Neurol 1985;232:295-300.

34 Kurtzke JF. The current neurologic burden of illness and injury in the United States. Neurology 1982;32:1207-14.

35 Scottish MND Research Group. The Scottish motor neuron disease register: a prospective study of adult-onset motor neuron disease in Scotland. F Neurol Neurosurg Psychiatry 1992;55:536-41.

36 Belsh JM. Epidemiology and historical perspectives of ALS. In: Belsh JM and Schifman PL, eds. Amyotrophic lateral sclerosis: diagnosis and management for the clinician. New York: Futura 1996: 3-8.

37 Rosser A, Hodges JR. Initial letter and semantic category fluency in Alzheimer's disease, Huntington's disease, and progressive supranuclear palsy. F Neurol Neurosurg Psychiatry 1994;57:1389-1394.

38 Abrahams S, Goldstein LH, Al-Chalabi A, et al. Relation between cognitive dysfunction and pseudobulbar palsy in amyotrophic lateral sclerosis. $\mathcal{f}$ Neurol Neurosurg Psychiatry 1997; 62:464-72. 